\title{
Advances in Visualization of the Early Human Development
}

\author{
${ }^{1}$ Iva Lausin, ${ }^{2}$ Asim Kurjak, ${ }^{3}$ Ritsuko K Pooh, ${ }^{4}$ Guillermo Azumendi, ${ }^{5}$ Kazuo Maeda \\ ${ }^{1,2}$ Department of Obstetrics and Gynecology, Medical School University of Zagreb, Sveti Duh Hospital, Zagreb, Croatia \\ ${ }^{3}$ CRIFM Clinical Research Institute of Fetal Medicine PMC, Osaka, Japan \\ ${ }^{4}$ Ultrasound Unit, Clinica Gutenberg, Malaga, Spain \\ ${ }^{5}$ Professor Emeritus, Department of Obstetrics and Gynecology, Tottori University School of Medicine, Yonago, Japan
}

Correspondence: Iva Lausin, Department of Obstetrics and Gynecology, Medical School University of Zagreb, Sveti Duh Hospital, Sveti Duh 64, Zagreb, Croatia, e-mail: lausiniva@yahoo.com

\begin{abstract}
The anatomy and physiology of placental and embryonic development is a field where medicine exerts its impact on early pregnancy and opens fascinating aspects of embryonic differentiation. The introduction of high frequency transvaginal transducers as well as three and four dimensional sonography has resulted in remarkable progress in ultrasonic visualization of early embryos and fetuses.

Ultrasound has been widely used in the field of early human development due to its safety, diagnostic accuracy and convenience. Normal fetal anatomy and development have been widely investigated using two-dimensional ultrasound and most of the knowledge regarding early human development were established through understanding of sectional images of fetal body and organs obtained by two-dimensional ultrasound. Usage of new techniques has produced more objective and accurate information of embryonal and early fetal development. For the first time parallel analyses of structural and functional parameters in the first 12 weeks of gestation become possible. This article deals with establishment of human life from ovum and sperm, though fertilization, detailed histological development and the establishment of the placenta, and early human development visualized by 2- and 3-dimensional ultrasonography.
\end{abstract}

Keywords: First trimester, sonoembriology, placenta, three-dimensional ultrasound.

\section{INTRODUCTION}

Controverses appear every time when question about beginning of the human life is raised.

Does human life begin when oocyte and spermatozoon come together, or when the baby is born, or when the person is accepted by the society? It is difficult to answer that question from the scientific point of view. Often, answer of that question is the matter of the religion.

Since the introduction of high frequently transvaginal transducer, ultrasonographic visualization of embryos and fetuses in early stage has been remarkably progressed and sonoembriology has been established. ${ }^{1}$

With the development of the science and newer and better technological approaches it is possible to detect and describe development of human life in its early stages. Development of ultrasound made it possible to detect product of conception just few days later after it reaches the uterus.

New technologies offer fascinating aspects of visualization of embryonic differentiation and early pregnancy development. Recent introduction of three- and four-dimensional ultrasonography offer a noninvasive tool of diagnostics and assessment of embryological phenomenon.

To demonstrate embryos and early fetuses in utero, transvaginal 3D ultrasound with $12 \mathrm{MHz}$ transducer enabled to produce highly sophisticated images demonstration spinal tube of $5.5 \mathrm{~mm}$ long embryo, detailed intracranial structures, internal vascularity, facial appearance, craniofacial ossification, thoracoabdominal organs and skeletal structures. ${ }^{1}$

\section{ULTRASOUND ASSESSMENT OF PRECONCEPTION}

Introduction of the color Doppler made it possible to visualize blood vessels, which enabled detailed examination of small vessels such arteries supplying preovulatory follicle, corpus luteum or endometrium (Fig. 1). Perifollicular vascularization can help in identification of follicles that are containing high-quality oocytes with a high probability of recupearing, 


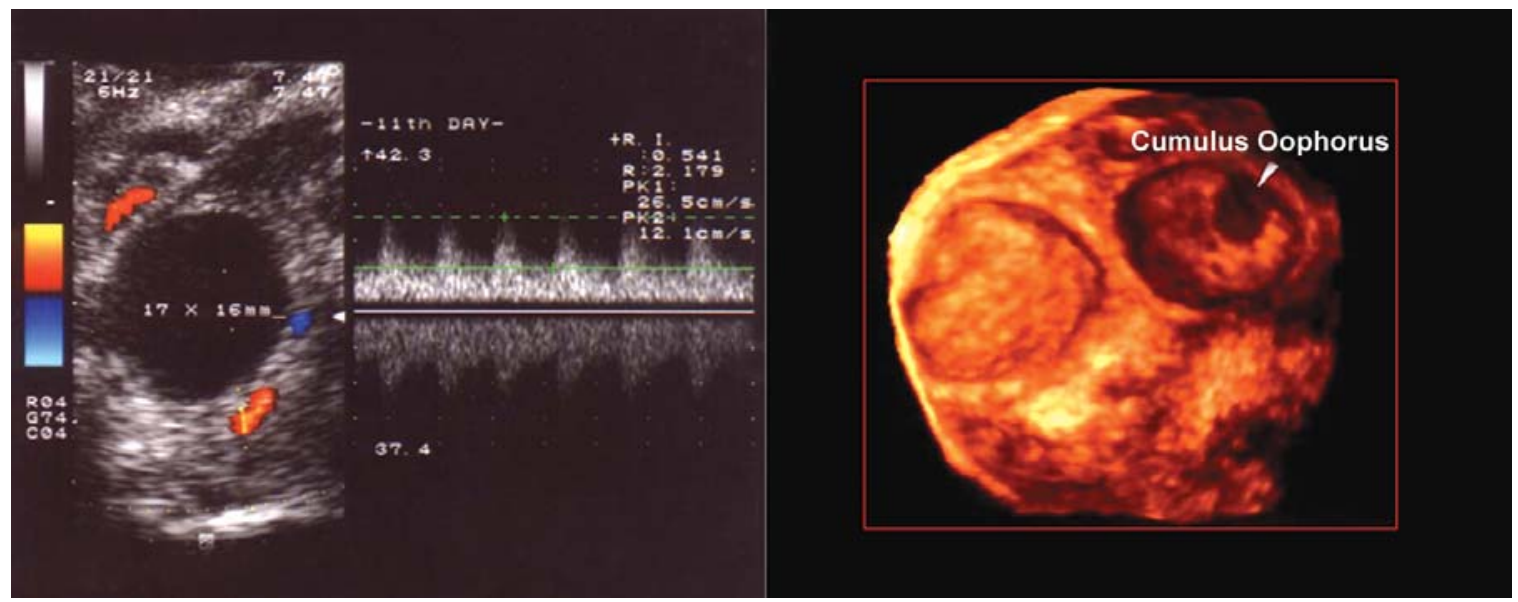

Fig. 1: In the left side of the image Color Doppler makes possible to depict the vascularization of follicles helping to identify those follicles which contain high quality oocytes. With an addition of three-dimensional ultrasound, it is possible to detect that ovarium contains two follicles; one empty, and other containing cumulus oophorus

fertilizing, cleaving and implanting. 3D ultrasound makes it also possible to visualize cumulus oophorus (Fig. 1). ${ }^{2}$

Fertilization is the end of the complicated process of junction of gametes by entering one spermatozoon into the oocyte. The gametes, ovum and sperm, contain half of the number of the chromosomes (haploid) comparing to the number present in somatic cells (diploid) (Fig. 2). They obtain haploid number of cromosomes through the process of meiosis during the gametogenesis., ${ }^{3,4}$ The oocyte is approximately 120 um in diameter and has a thick membrane known as zona pellucida.

The spermatozoon moves using the flagellum or tail, and the total length of the spermatozoon including the tail is 60 um. $^{2}$ Both oocyte and spermatozoon are highly specialized sex cells. Oocytes are produced in the ovary and expelled from it during the ovulation after which fimbriae of the fallopian tube sweep the oocyte into the ampulla where, it can be fertilized. When sperm enters the oocyte, the nucleus of the mature oocyte consist the female pronucleus and the head of the sperm separates from the tail and enlarges to become male pronucleus. Fertilization is complete, when, the pronuclei unite and the maternal and paternal chromosomes intermingle during metaphase of the first mitotic division of the zygote (Fig. 2). That cell that is the primordium of the human being. ${ }^{5}$

Transfer of the oocyte is faciliated by the changing endocrine milieu of the early luteal phase with its rising ratio of progesterone to estrogen, which affects the oviductal and uterine musculature and relaxes the isthmic sphincter. It is probable, however, that the cilia, rather than the musculature are the primary active transporters of the conceptus. Thus, pharmacological inhibition of oviductal muscles do not prevent transfer of the conceptus. Furthermore, if a segment of oviduct is excised, turned around and replaced such that cilia beat away from the uterus, the conceptus moves to that part of the oviduct and then it stops (Fig. 3). ${ }^{3}$

Already few minutes after the ovulation oocyte is located in the ampullar part of the fallopian tube. It is surrounded by the zona pellucida. On the surface of the zona pellucida there are few rows of the granulosa cells, which make corona radiata. Peripherial of the corona radiata are left cells of cumulus oophorus. Often, these three units are called oocytecorona-cumulus complex. Capability for the fertilization is limited: oocyte can be fertilized only 6 to 12 hours after the ovulation. Sperms are capable for fertilization 48 to 72 hours, until they are movable. Fertilization occurs in the ampullar part of the fallopian tube. ${ }^{6}$ The process of fertilization begins with conditioning of the spermatozoon in the male and female reproductive tracts. Thereafter, fertilization involves not only the egg itself but also the various investments that surround the egg in the time it is released from the ovary folicle. Fertilization is not an event, it is a complex biochemical process requiring a minimum of 24 hours to complete syngamy (forming of a diploid set of cromosomes). During that process there is no commingling of maternal and paternal chromosomes within a single nuclear membrane (prezygote); after this process, the paternal chromosome material is commingled (zygote) with the recognition of the new genome which presents the principal information center for the development of the human being and for all its further activities. $^{2}$ 

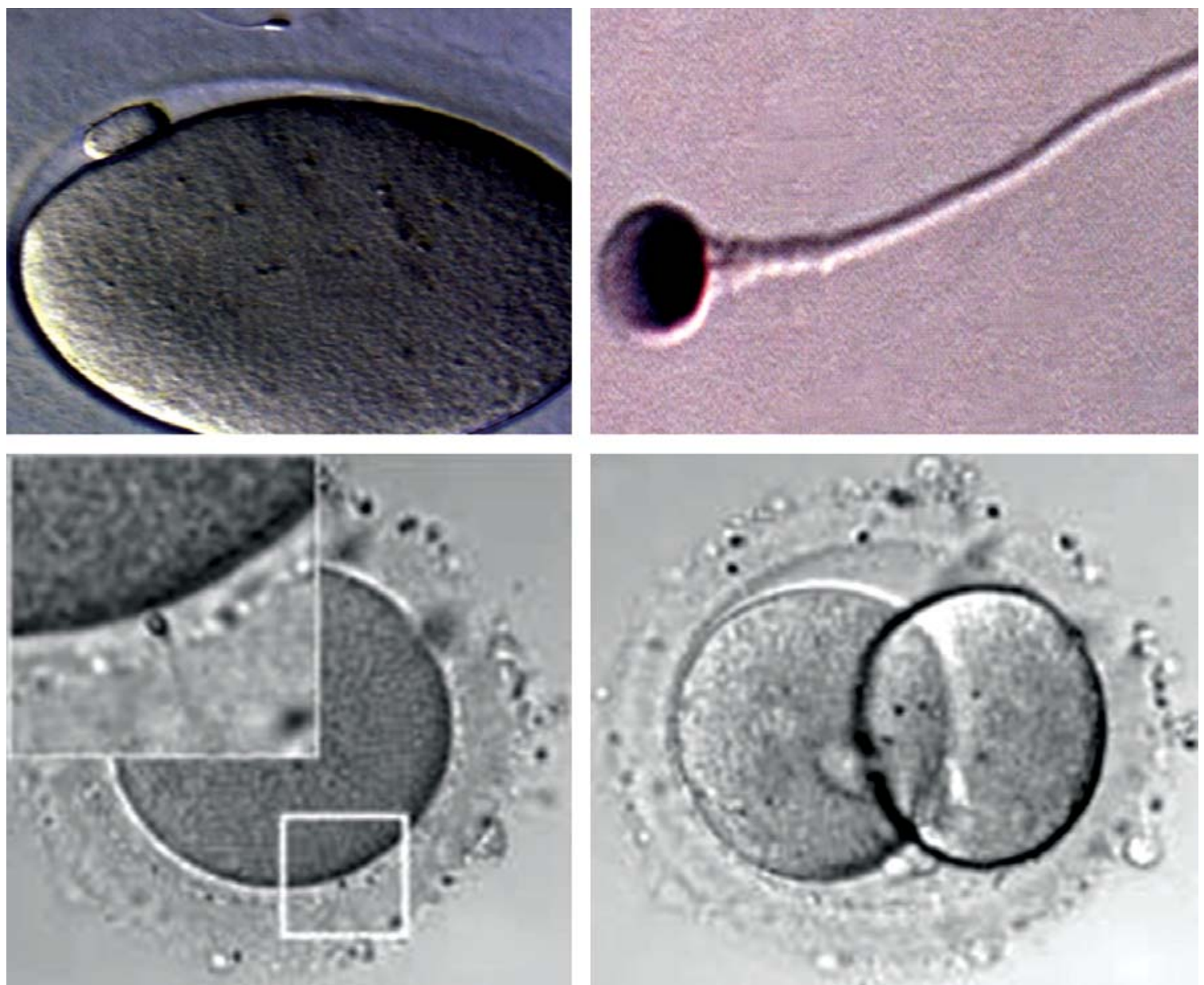

Fig. 2: Phase contrast images of ovum and sperm, fertilization and first cleavage

\section{ULTRASOUND ASSESSMENT IN EARLY DEVELOPMENT OF THE EMBRYO AND THE ESTABLISHMENT OF THE PLACENTA}

After syngamy, the zygote undergoes mitotic cell division as it moves down the fallopian tube towards the uterus. Shortly after gene activation conceptus shows marked quantitative increase in its biosynthetic capacity. Net synthesis of mRNA and protein increase, transport of amino acids and nucleotids into the cells rises and changes occur in the synthetic patterns of phospholipids and cholesterol. The growth and methabolic activity of the preimplatation conceptus in vitro has been shown to be stimulated by a number of growth factors which vary between species and include: Insuline like growth factors (IGF-1 and 2), transforming growth factors alpha (TGF-alpha) and (TGFbeta 1 and 2), epidermal growth factor (EGF), plateletderivated factor A (PDGF-A). ${ }^{3}$

A series of mitotic divisions lead to the development of the pre-embryo. The newly devided cells are called

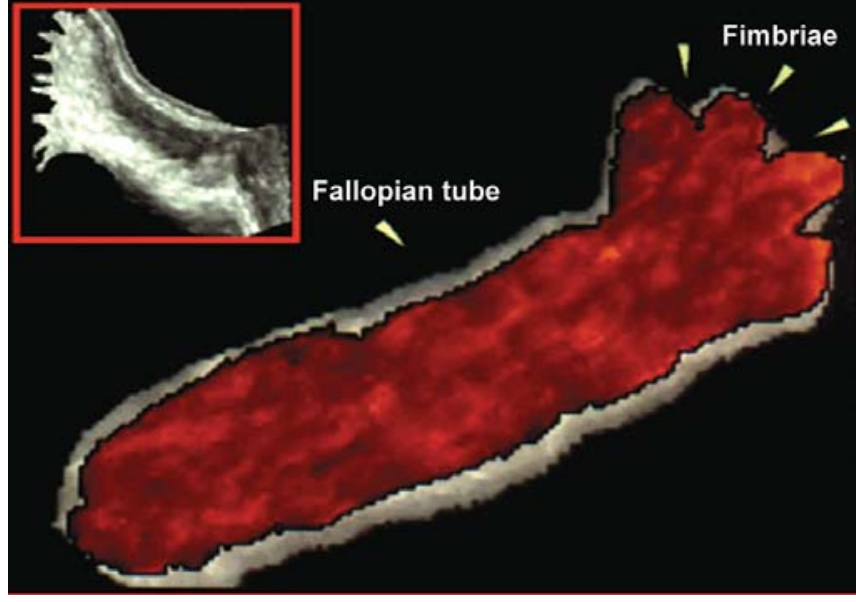

Fig. 3: A 3D power Doppler image showing fallopian tube. Power Doppler shows movement of the fluid going through the fallopian tube confirming that it is possible to pass through it

blastomeres. From 1 to 3 day after syngamy, there is a division into 2 cells and then 4 cells. Blastomeres form cellular aggregets of distinct, totipotent, undifferentiated cells that retain the capacity to develop independently into normal 


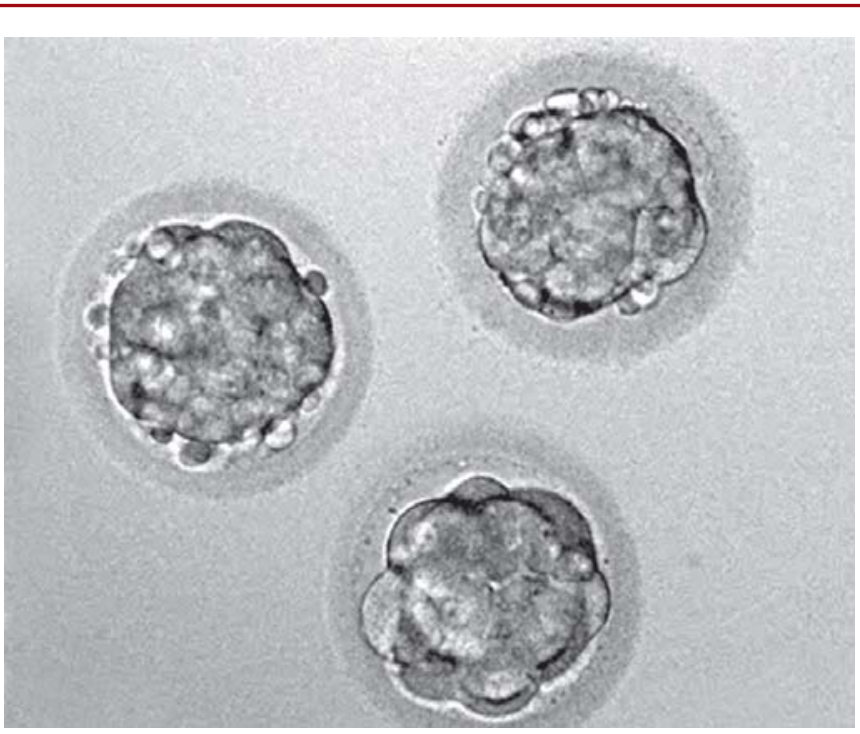

Fig. 4: Phase contrast image of blastocyst formation

pre-embryos. ${ }^{2}$ After every division blastomeres become half of their previous size keeping total size the same as in the beginning when it was just one cell. All up to 8 call phase blastomeres are cluster of cells inside the zona pellucid (Fig. 4).

But, after the third division they lose their round shape and they impact one to the another making compact round cluster of cells, which are tightly connected by tight junctions. With that change, which is called compaction, cells from the outside start to differentiate from those inside. Third day after the fertilization cells of the compact embryo divide again and morula occurs. Morula stage is reached when about 12 to 16 cells are present, outer part from which trophoblast will appear, and inner cells from which embryo will appear. ${ }^{7}$
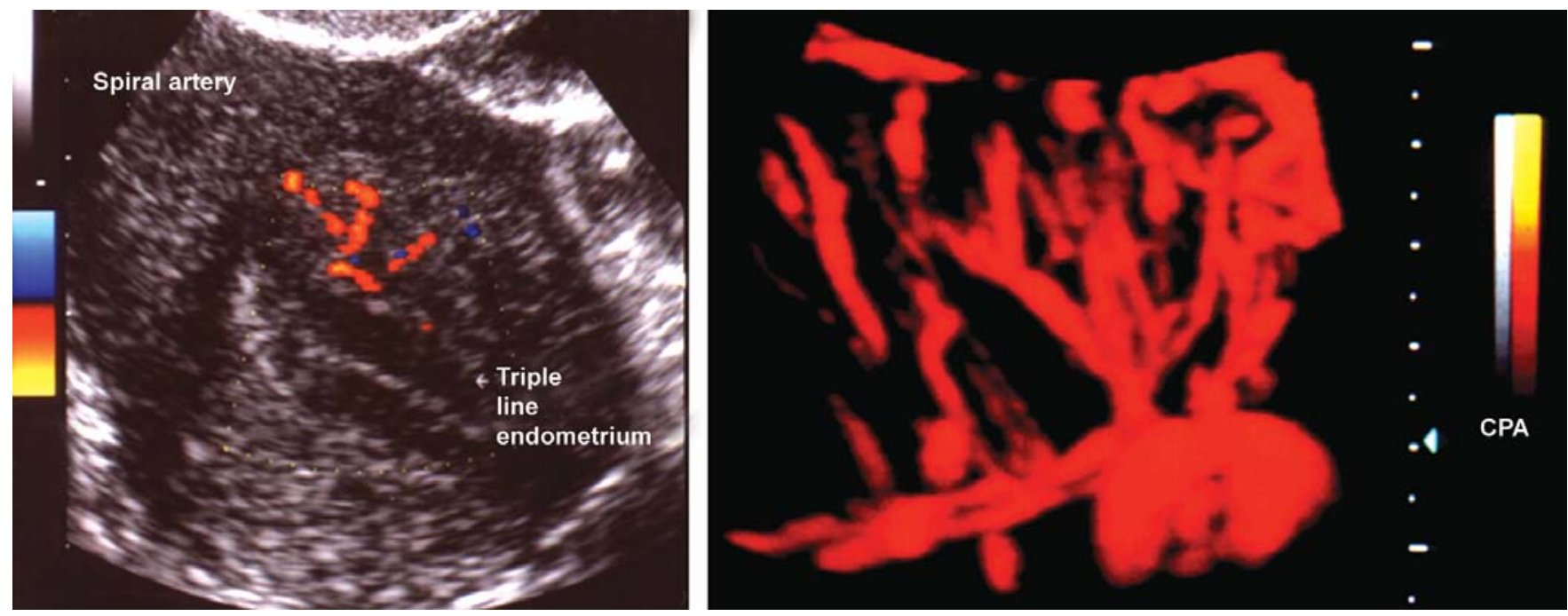

Fig. 5: A 2D and 3D power Doppler image showing spiral arteries supplying triple-line endometrium, important for future implantation. In the time when blastocyst is prepared for implantation, in the middle of the lutheal phase of cycle, endometrium is about 10 to $14 \mathrm{~mm}$ thick
In the time, when morula enters the uterine cavity blastocyst appears (Fig. 4). A blastocyst is an embryo, which has developed to the point of having 2 different cell components and a fluid cavity. Inner part of the cells is then called embryoblast and it is located on the one side of the blastocyst. Outer part of cells is trophoblast and it makes epithelial surface of the blastocyst. ${ }^{7}$ The expansion of the blastocele is stimulated by growth factors EGF and TGFalpha. ${ }^{3}$ Throughout the development, from fertilization to the blastocyst, conceptus remains enclosed in zona pallucida. The zona pellucida is the extracellular matrix that plays important roles in sperm-egg interaction. The zona pellucida is composed of three major glycoproteins that exhibit heterogeneity due to extensive post-translational modifications including glycosylation and sulfation. Studies have now shown that the proteins of the $\mathrm{ZP}$ are expressed in a stage specific manner and that there is increasing evidence that zona pellucida proteins are expressed by both granulosa cells and the oocyte and may play a role in granulosa cell differentiation. ${ }^{8}$ Also, it prevents blastomeres of the conceptus from falling apart during early cleavage period prior to compaction. It prevents two genetically distinct conceptuses forms ticking together to make a single chiameric conceptus. ${ }^{3}$ Hatched blastocyst is bathed in uterine secretions from which it draws the oxygen and methabolic susptrates important for growth and survival. There is the limit of the size that free living conceptus can attain before such exchanges become inadequate. Before that critical stage is reached, conceptus grows its own blood vascular system. 
When blastocyst leaves zona pellucida, it makes it possible for blastocyst to implant into the endometrium. Adequate thickness of triple-line endometrium and ingrowth of spiral arteries are important for future implantation (Fig. 5). Once entering the uterus, the conceptus engages in an elaborate interaction with the mother in which several messages by establishing physical and nutritional contact with the maternal endometrium at the implantation. Second, conceptus signals its presence to maternal pituitary-ovarian axis; somehow, it must convert the whole female reproductive system from cyclic pattern to a noncyclic in which progesterone dominates.

Different changes in endometrium have been studied with goal to predict successful implantation. In the study of Zohav and colleagues they have shown that the dynamic changes in endometrial volume and thickness between day of embryo transfer and two weeks later may predict IVF treatment outcome. ${ }^{9}$

A good blood supply towards the endometrium is usually considered to be an essential requirement for implantation and therefore assessment of endometrial blood flow in IVF treatment has attracted a lot of attention in recent years. ${ }^{10}$ Doppler study of uterine arteries does not reflect the actual blood flow to the endometrium. Endometrial and subendometrial blood flows can be more objectively and reliably measured with three-dimensional power Doppler ultrasound. However, conflicting results are reported with regard to their role in the prediction of pregnancy in IVF treatment. $^{10}$

Endometrial development is largely dependent on a good blood supply to the basal endometrium. The study of $\mathrm{Ng}$ and collegues evaluated the endometrial and subendometrial vascularity in patients with thin $(\leq 8 \mathrm{~mm})$ endometrium and in those with low volume $(\leq 2.5 \mathrm{ml})$ endometrium. It was found that 3D power Doppler flow indices of the endometrial and subendometrial regions were significantly lower in patients with low volume endometrium compared with those with normal volume endometrium. Endometrial and subendometrial vascularity measured by 3D power Doppler ultrasound was significantly lower in patients with low volume endometrium, but not in those with thin endometrium. ${ }^{11}$

In the time, when blastocyst is prepared for implantation, in the middle of the lutheal phase of cycle, endometrium is about 10 to $14 \mathrm{~mm}$ thick. It is prepared for the implantation by various factors: EGF, IGF-I, and local paracrine and autocrine factors. From day 16 to 22 receptivity of the endomterium is highest, that time is called "implantation window". When blastocyst leaves zona pellucida, it makes it possible for conceptus to make contact with decidual endometrium. Implantation consists of 3 phases: aposition, adhesion and invasion. Aposition and adhesion are assisted with adhesive molecules of endometrium like laminin, fibronectin, and receptors like integrins. Conceptus produces signals which make change in mother's bloodflow. It produces early pregnancy factor (EPF) which has immunosuppresive effect. By the beginning of the implantation proteases and matrix metaloproteinases are activated. Conceptus which is close to the surface of the endomterium begins its invasion. Enzymes of the trophoblast invade mother's circulation and build hematochorial placentation. ${ }^{6}$

The invasiveness of the conceptus is influenced by the effectiveness of the decidual response.

The invasiveness of the trophoblast depends of the expression and regulation of the different proteolytic enzymes. TGF-beta promotes decidualization and controls trophoblastic invasion. Histamine and prostaglandins are involved in the stromal response: inhibition of either one of them reduces the decidualization.

An important feature of decidual response is increase in vascular permeability and growth of new capillaries (angiogenesis) (Fig. 6).

\section{FIVE TO SIX WEEKS OF PREGNANCY}

A small intradecidual gestation sac can be seen by transvaginal sonography between 32 and 34 days (Fig. 7). It can be visualized from the middle of the fifth week of amenorrhea as a small anechoic oval or rounded shaped structure placed inside one of endometrium leafs. Threedimensional sonography enables precise measurement of the exponentially expanding gestational sac volume during the first trimester.

The secondary yolk sac is the earliest extraembryonic structure normally seen within the gestational sac beginning of the 5th gestational week (Fig. 8). The yolk sac is seen when diameter of the gestational sac is approximately 8 mm using transvaginal probe. Yolk sac volume increases from week 5 to 10 . When it reaches its maximum at the week 10 it already starts to degenerate, which can be seen by the significant reduction in visualization rates of the yolk sac vascularity. 

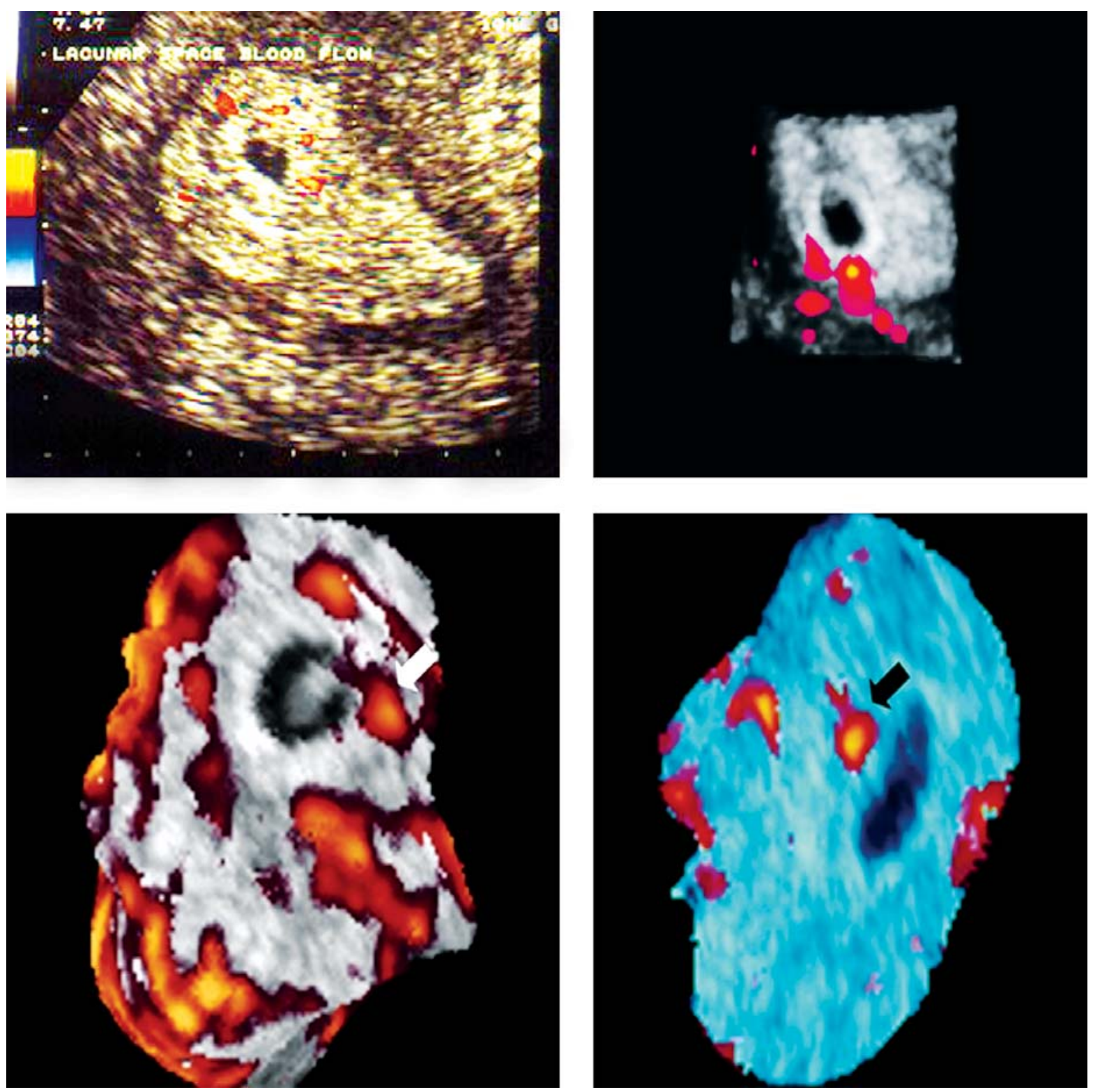

Fig. 6: Decidual response to implanted pregnancy: ingrowth of new capillaries-angiogenesis. The increase of permeability and growth of new capillaries is present. At the beginning of the fifth week, embryonic echo and yolk sac are still not visible. Spiral arteries open up in the early intervillous space. Increased blood flow that surrounds the gestational sac is a direct consequence of the dilatation of spiral arteries by the trophoblast proteolytic activity. Full complexity of vascular network of spiral arteries and intervillous flow under the placenta can be assessed and depicted using the 3D power Doppler

The embryo can be depicted one or two days after the visualization of the yolk sac, at that time it is 2 to $3 \mathrm{~mm}$ long. The embryonic heart begins beating on about day 22 or 23, accepting blood components from the yolk sac and pushing the blood into the circulation (Fig. 9). The embryonic blood begins circulating at the end of the fifth week of the development.

The start of embryo-chorionic circulation changes the source of nourishment to all intraembryonic tissues.
Development of the embryo becomes dependent on the circulation of embryonic blood. In the embryo, there are 3 distinct blood vasculary systems: vitelline circulation (from yolk sac to embryo), intraembryonic circulation and fetoplacental circulation. It is possible to visualize and assess them virtually from conception.

At 5 weeks it is possible to obtain 3-dimensional image of the developing intervillous circulation in the maternal site of placenta. Doppler shows intense vascular activity 

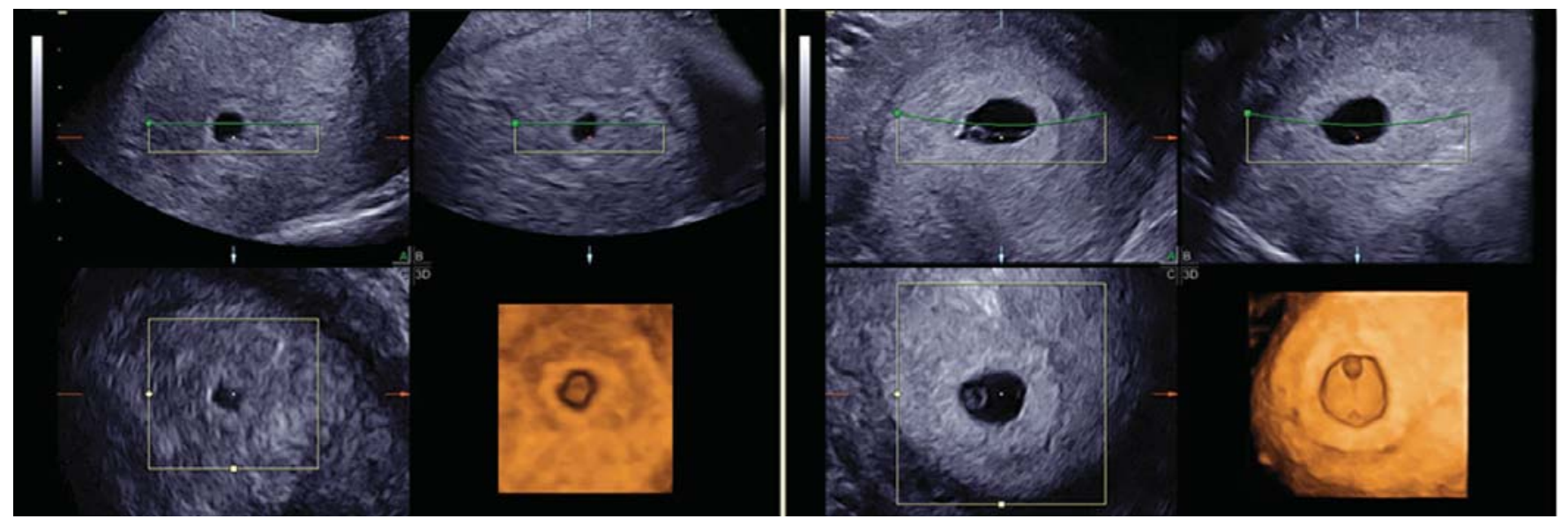

Fig. 7: A 3D Image of five weeks old pregnancy. New softwares make it possible to measure the growing volume of gestational sac

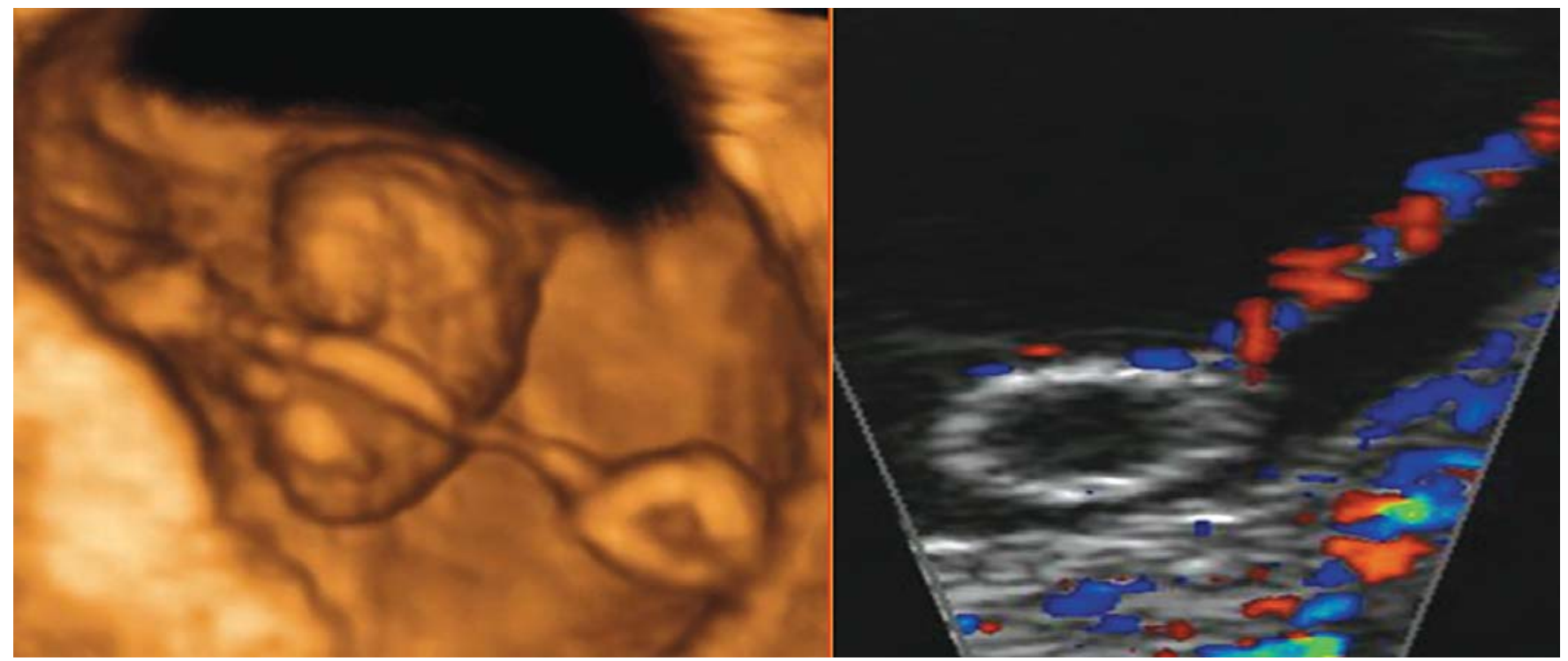

Fig. 8: A 3D image of embryo and yolk sac on the left. Right image showing vascularization of the yolk sac. At the tenth weeks it loses its function and begins to degenerate, losing its vascularity
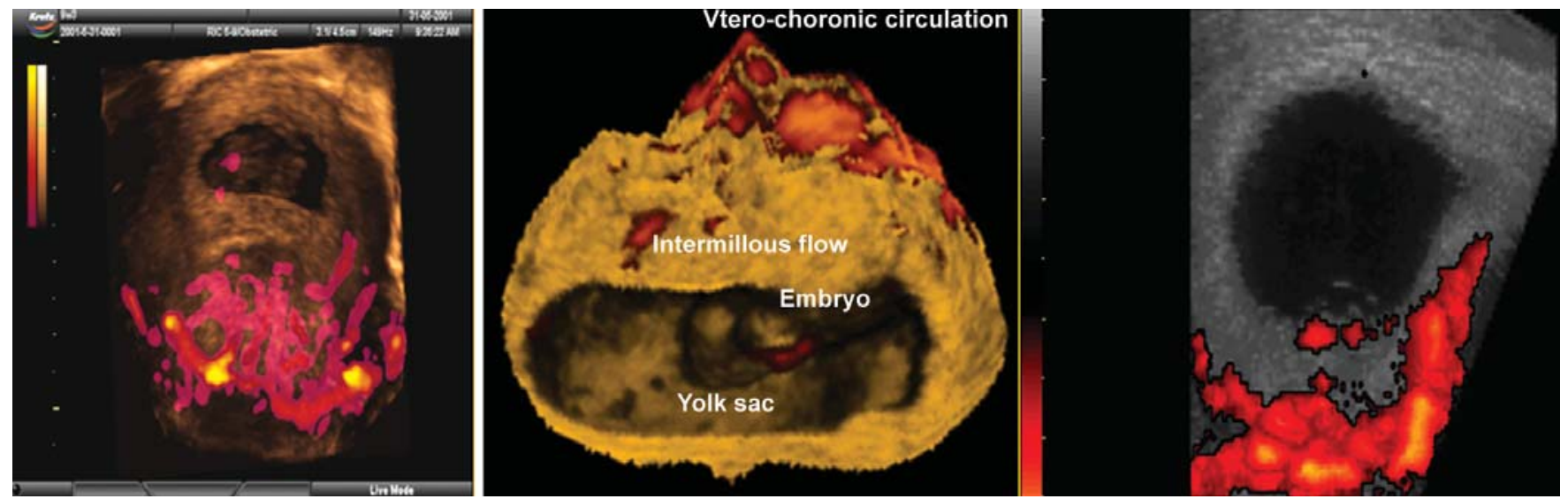

Fig. 9: A 3-dimensional image of the developing intervillous curculation in the maternal site of placenta at fifth week of gestation. Doppler shows intense vascular activity surrounding the chorionic shell 


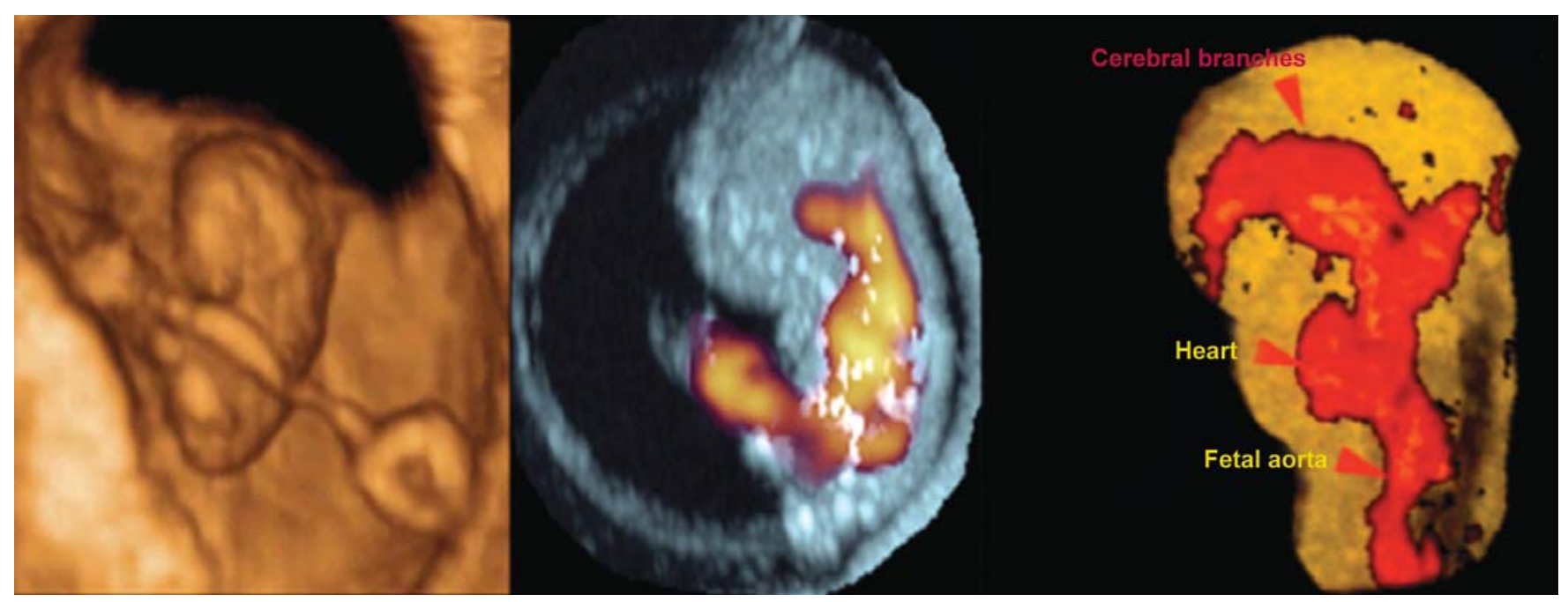

Fig. 10: A 3D power Doppler image od fetal circulation. Parallely with growing of embryo its vascularity branches. At eight weeks of gestation vascularity in embryos brain and heart can be depicted

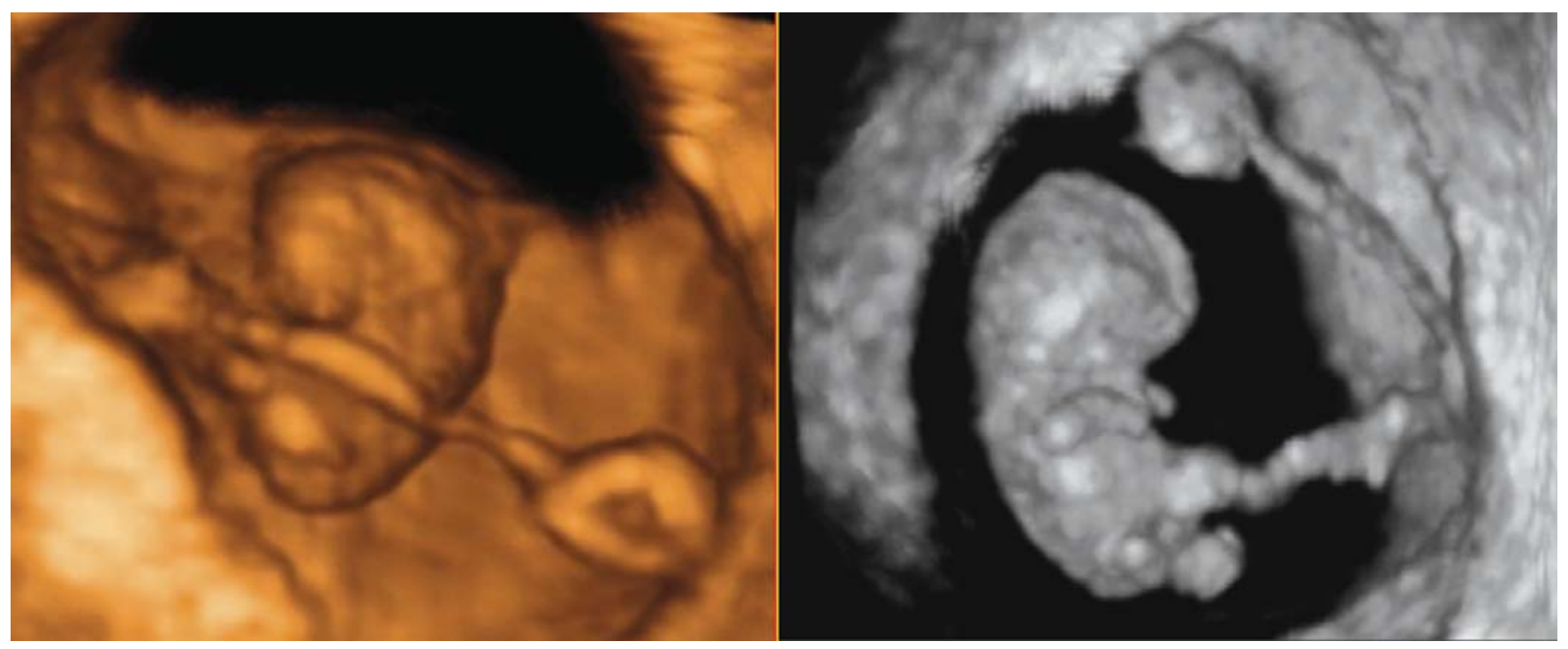

Fig. 11: Seven to eight weeks of pregnancy, 3D image shoving bulky head almost the same size as the rest of the body. Yolk sac is clearly visualized as well as the first signs of development of embryos limbs

surrounding the chorionic shell starting from the first sonographic evidence of the developing pregnancy during the fifth week of gestation (Fig. 9). At 7 weeks 3D power Doppler images depict aortic and umbilical blood flow (Fig. 10). The initial branches of the umbilical vessels are visible at the placental umbilical insertion.

Six weeks embryo is visualized as a rounded bulky head and a thinner body. The head is prominent due to the development of the midbrain (Fig. 11). ${ }^{12}$ Limb buds are rarely visible in this stage of the pregnancy.

\section{SEVEN TO EIGHT WEEKS}

At the seventh week development of fetal brain continues and development of the rombencephalon takes place. With the use of the planar mode developing vesicles of the brain can be depicted as anechoic structures inside of the head. The biggest, and usually the only visible, is rombencephalon placed on the top of the head. In the seventh week limbs can be visualized laterally to the body while the head is strongly flexed anterior. ${ }^{12}$ At the end of seven weeks of gestation, the distal end of the limb buds are flatten into hand and footplates (Fig. 11).

During the eight week the shape of the face is becoming apparent but the flexion of the cranial pole makes it difficult to view the face entirely (Figs 12 and 13). Between 7 and 10 weeks of gestation, the medial nasal prominences merge with each other forming a continuity of the upper jaw and lip. 

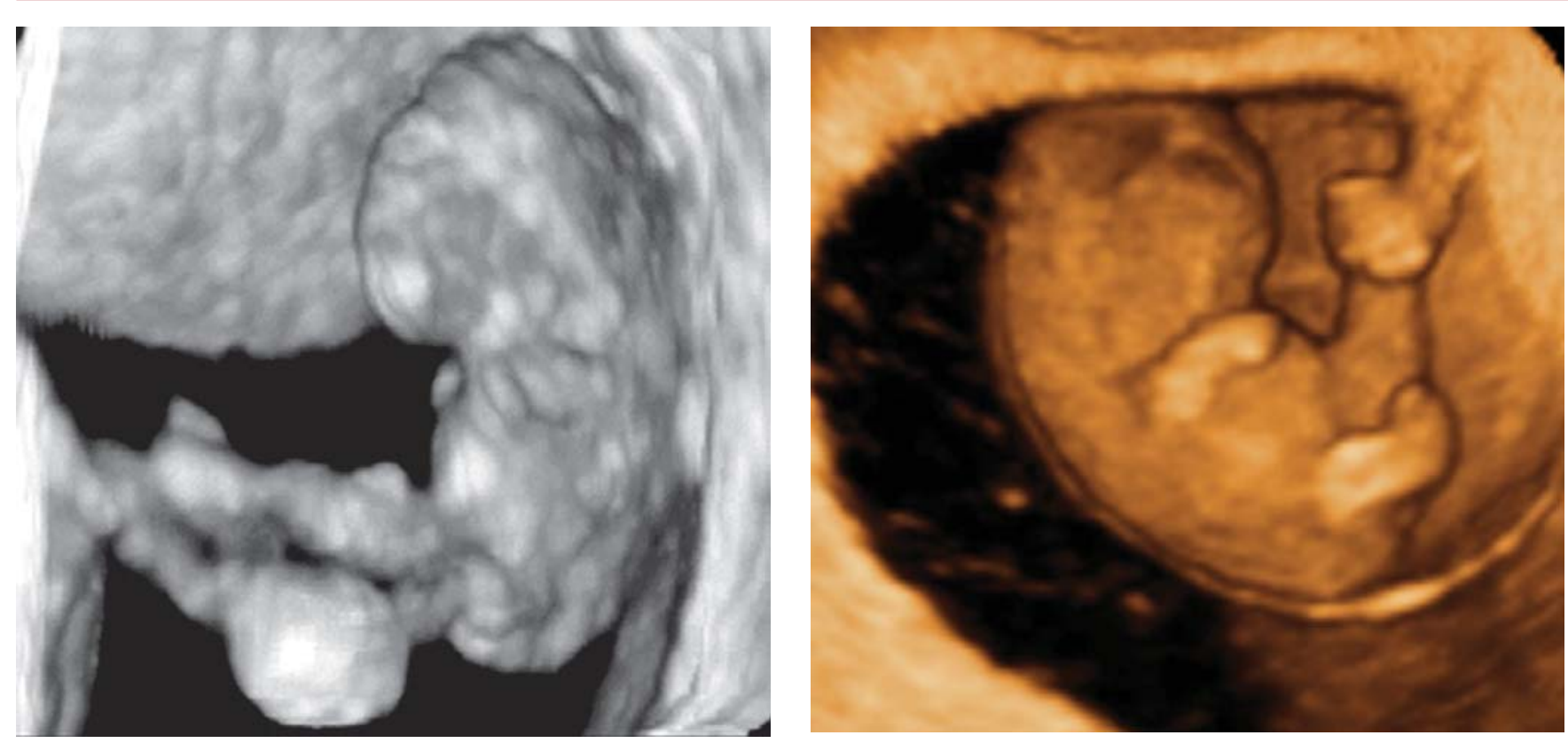

Fig. 12: In the eigth week of pregnancy face is becoming apparent

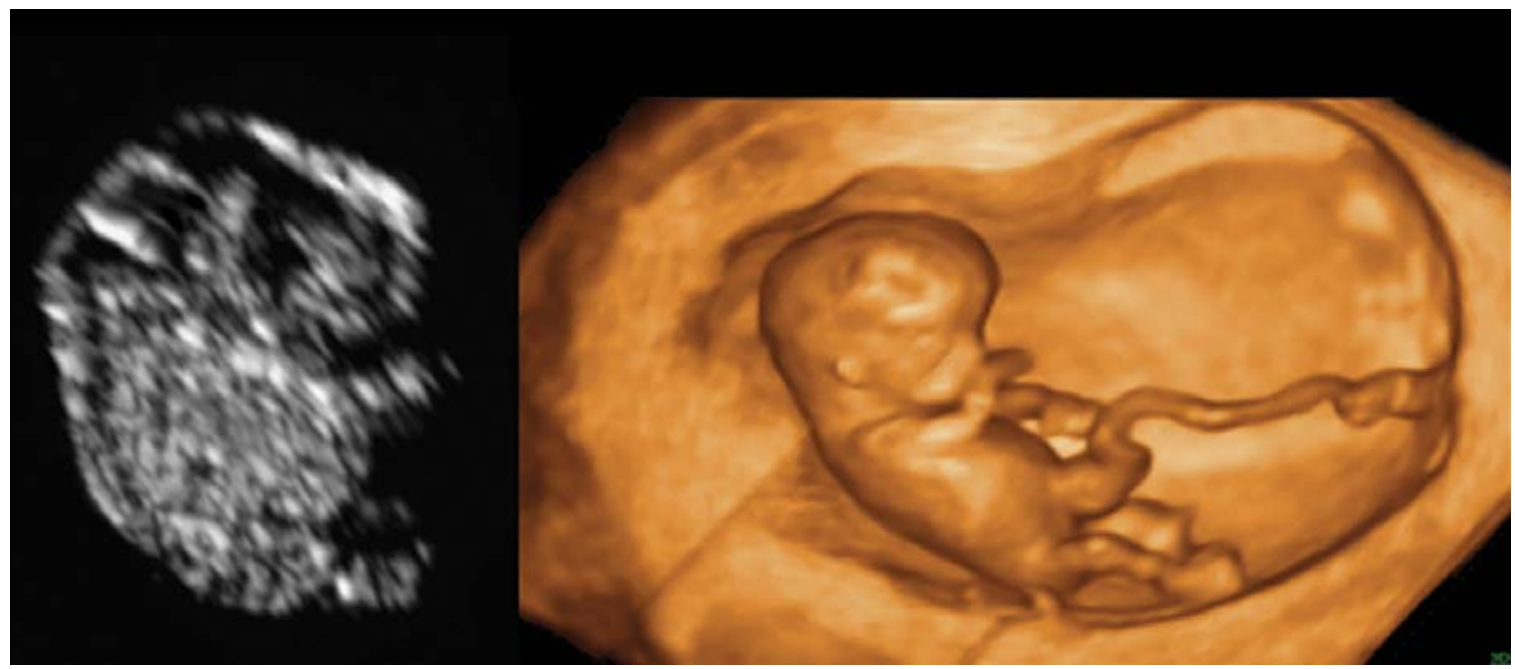

Fig. 13: Nine weeks old fetus. Image showing developing intracranial structures. 3D image shows developing fetal face details, legs, arms and fists. During eight week of gestation mesenchymal tissue in the hand and foot forms digital rays. Separate digits are formed by the end of the ninth week of gestation

The vertex is positioned over the position of the midbrain and the expansion of the ventricular system appears (lateral, third and midbrain ventricles). The ventricular cavities are characteristically cyst, particularly the rombencephalon. This should not to be confused with an early diagnosis of Dandy Walker cyst (Figs 13 and 14). ${ }^{12}$

Insertion of the umbilical cord is visible on the anterior abdominal wall (Fig. 15).

\section{NINE AND TEN WEEKS}

In the developing brain lateral ventricles containing hyperechoic choroid plexuses can be depicted (Fig. 16). The head is clearly divided from the body by the neck. Around 10 weeks of gestation eyes are widely separated, ears are low set, the nose is flat and the mandible is underdeveloped. 


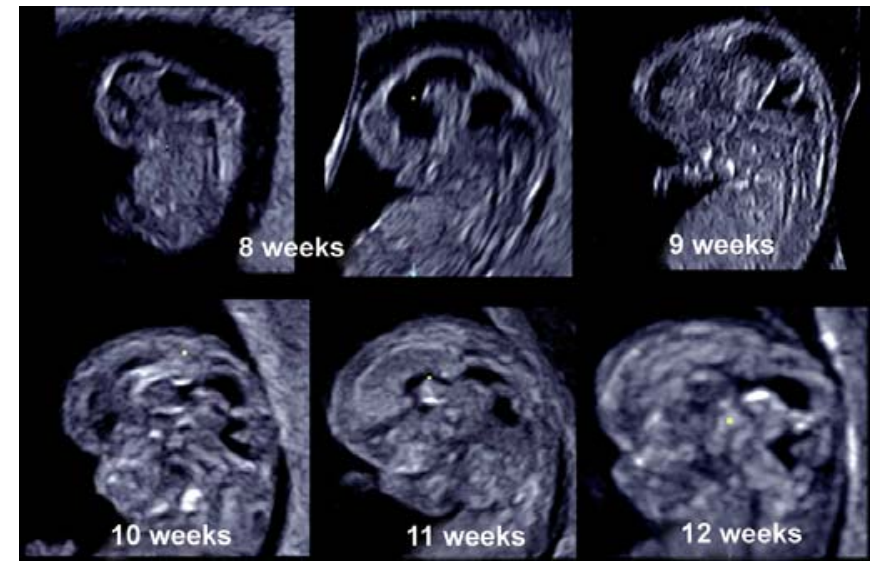

Fig. 14: Developing brain in early pregnancy. Fetal central nervous system changes in size and appearance from early premature structure into late mature structure with gyral formation. Eight weeks of pregnancy showing the development of the brain. In early embryonic period it appears as cystic formation. First, rhombencephalon is seen, fallowed with the development of mesencephalon and diencephalon. The ventricular cavities are characteristically cystic, particularly the rhombencephalon. This should not be confused with an early diagnosis of a Dandy Walker cyst

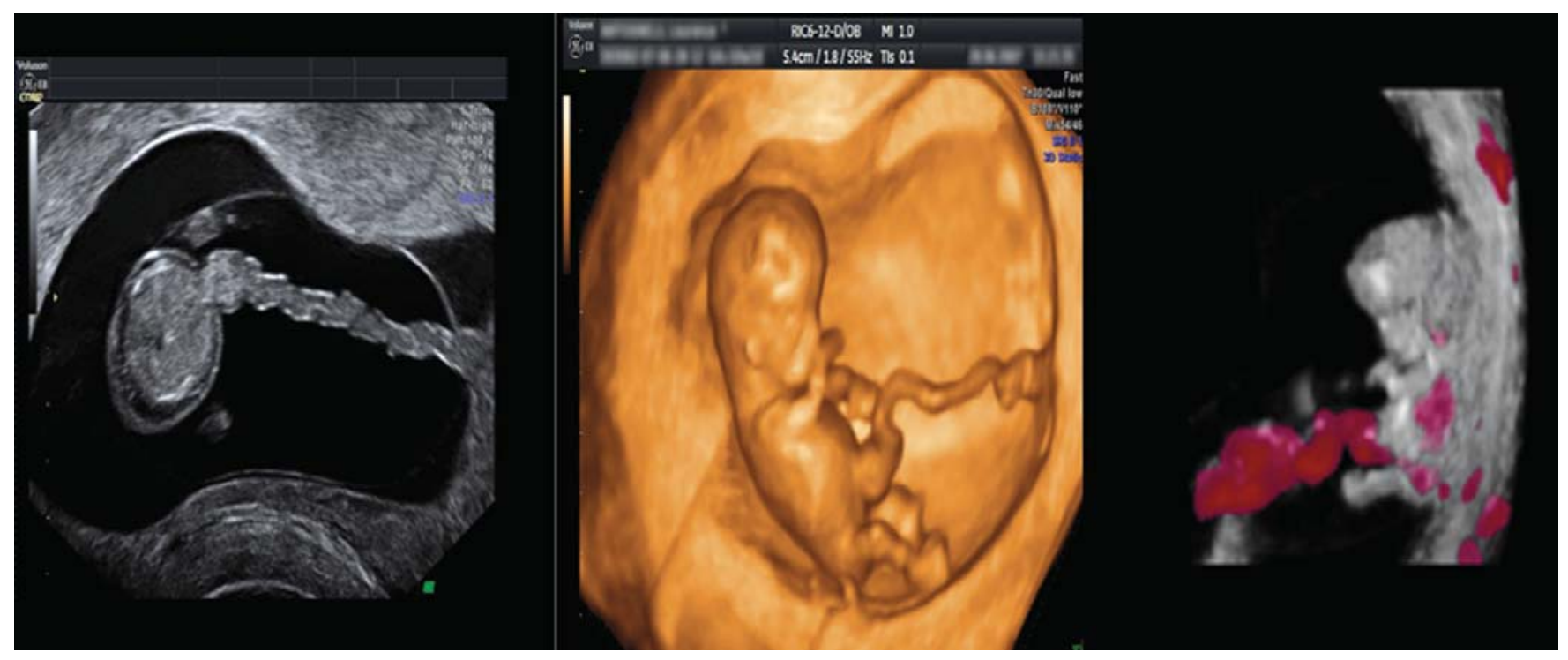

Fig. 15: Visualization of the umbilical cord and its vascularization using 2D, 3D and 3D power Doppler technique
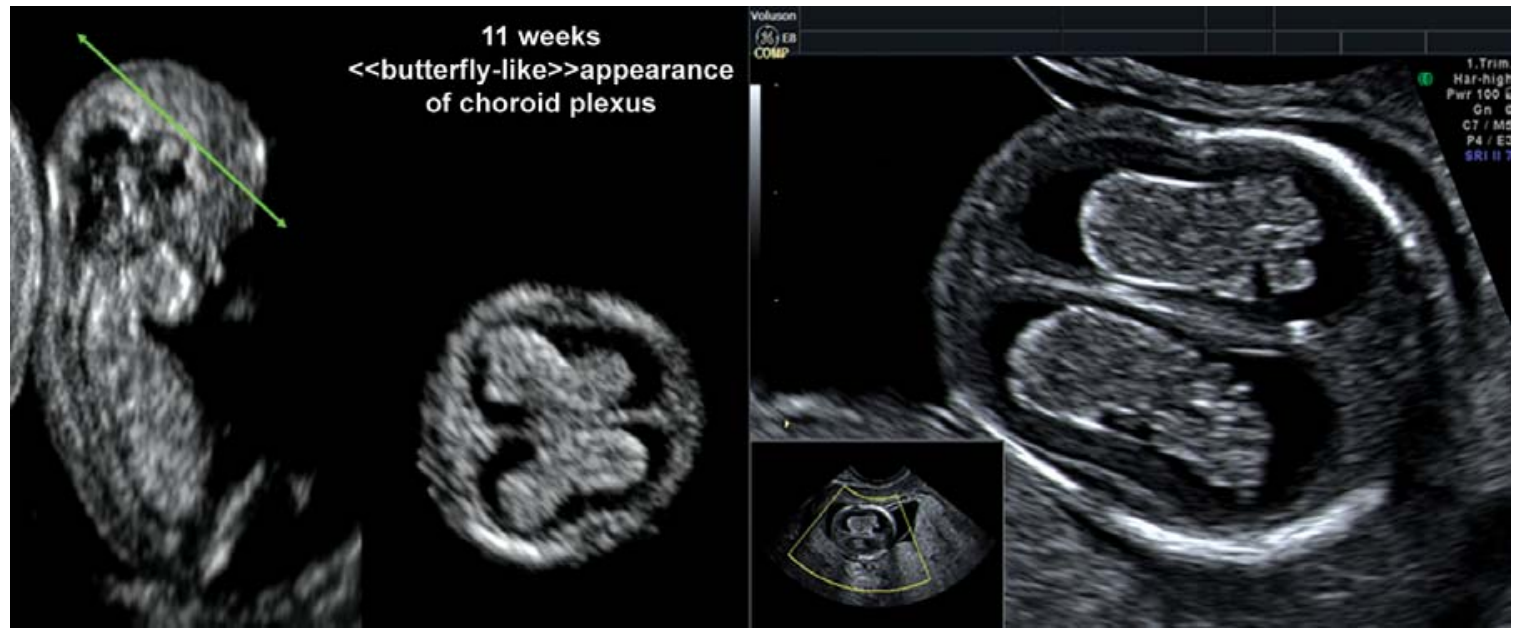

Fig. 16: Butterfly shaped choroid plexus—characteristic image at 11 weeks of pregnancy 


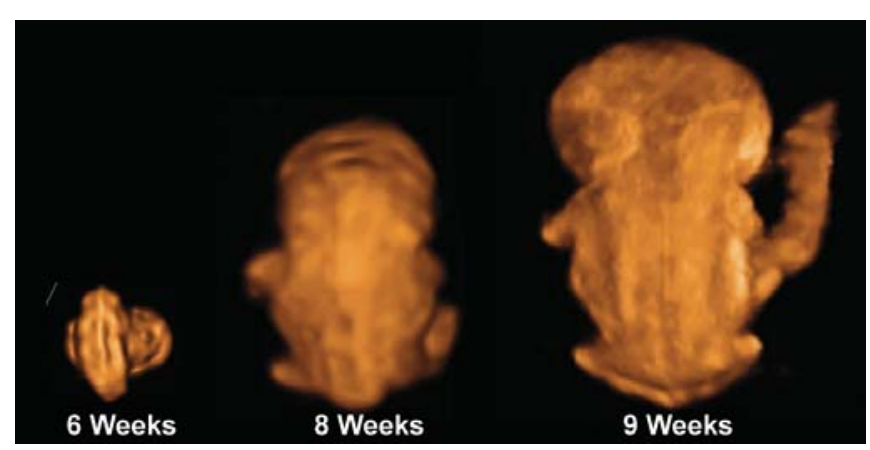

Fig. 17: In the ninth week of pregnancy earlys spine can be examined in its whole length

In this period of time, umbilical herniation is a normal finding in fetus. The abdominal cavity is too small to accommodate rapidly growing intestins. Untestins return to the abdominal caviy during eleventh week of gestation.

During the ninth week of gestation the upper limbs are bent at the elbow and hands are curved over the thorax.

Dorsal column, the early spine can be examined the whole length (Fig. 17). The arms with elbows and legs with knees are visible. Blaas and collegues reported successful detection of three cases of lumbosacral myelomeningocele. ${ }^{13}$

Internal vascularity in an early fetus can be visualized by 3D power Doppler imaging. This enables research of longitudinal changes in embrynic and early uteroplacental circulation. This enables research of longitudinal changes in embryonic and early uteroplacentar circulation. Premature internal vascularity at 9 weeks of gestation can be depicted. ${ }^{1}$ By using recent 3D power Doppler technology, circulatory orientation can be clearly obtained and the common carotid arteries, internal carotid arteries, circle of Willisi and middle cerebral arteries are well visualized (Fig. 18). ${ }^{1}$

The umbilical artery is characterized by systolic pulsations with absent end-diastolic velocities. Between 11th and 14th weeks of gestation diastolic velocities gradually emerge. ${ }^{12,14}$

From maternal side of placenta 3D imaging of developing intervillous circulation during the first trimester of pregnancy is possible. 3D power Doppler reveals intensive vascular activity surrounding the chorionic shell starting from the first sonographic evidence during the fifth weeks of gestation. ${ }^{12,15}$

\section{NEW POSSIBILITIES FOR STUDYING EMBRYONIC AND FETAL MOVEMENTS AND BEHAVIOR}

The latest development of 3D and 4D sonography enables precise study of embryonic and fetal activity and behavior.
With 4D ultrasound movements of the head, body, and all four limbs and extremities can be seen simultaneously in three-dimensions. Therefore, the earliest phases of the human anatomical and motor development can be visualized and studied simultaneously. Neurologic development (i.e. early fetal motor activity and behavior) needs to be reevaluated by this new technique. ${ }^{16,17}$ Recently, our group studied the development of the complexity of spontaneous embryonic and fetal movements and produced the first scoring system for the assessment of fetal neurobehavior. ${ }^{16-19}$ With advancing gestational age, the movements become more complex. The increase in the number of axodendritic and axosomatic synapses between 8 and 10 weeks and between 12 and 15 weeks correlates with the periods of fetal movement differentiation and with the onset of general movements and complex activity patterns such as swallowing, stretching, and yawning, seen easily by $4 \mathrm{D}$ technique. At 7 to 8 weeks of pregnancy, gross body movements appear. They consist of changing the position of head toward the body. At 9 to 10 weeks of pregnancy, limb movements appear. They are characterized by the changing of position of extremities towards the body without the extension or flexion in elbow and knee. At 10 to 12 weeks of pregnancy, complex limb movements appear. This consists of changes in position of the limb segments toward each other, such as extension and flexion in elbow and knee (Fig. 19).

At 12 to 15 weeks of pregnancy, swallowing, stretching, and yawning activities appear. It is now feasible to study by 4D ultrasound a full range of facial expression, including smiling, crying, and eyelid movement. It is hoped that new 4D techniques will help us to better understand the somatic and motoric development of the early embryo. It will also enable the reliable study of fetal and parental behavior.

\section{CONCLUSION}

There has been a rapid acceleration in understanding the anatomy and physiology of placental and embryonal development due to the introduction of new 3D and 4D sonographic techniques. They from one of the most promising forms on noninvasive diagnostic and embryological phenomenon which now can be routinely recorded with outstanding clarity. Different approaches and ways of visualization of early human development accelerates the understanding of a big and important field of early human development. 

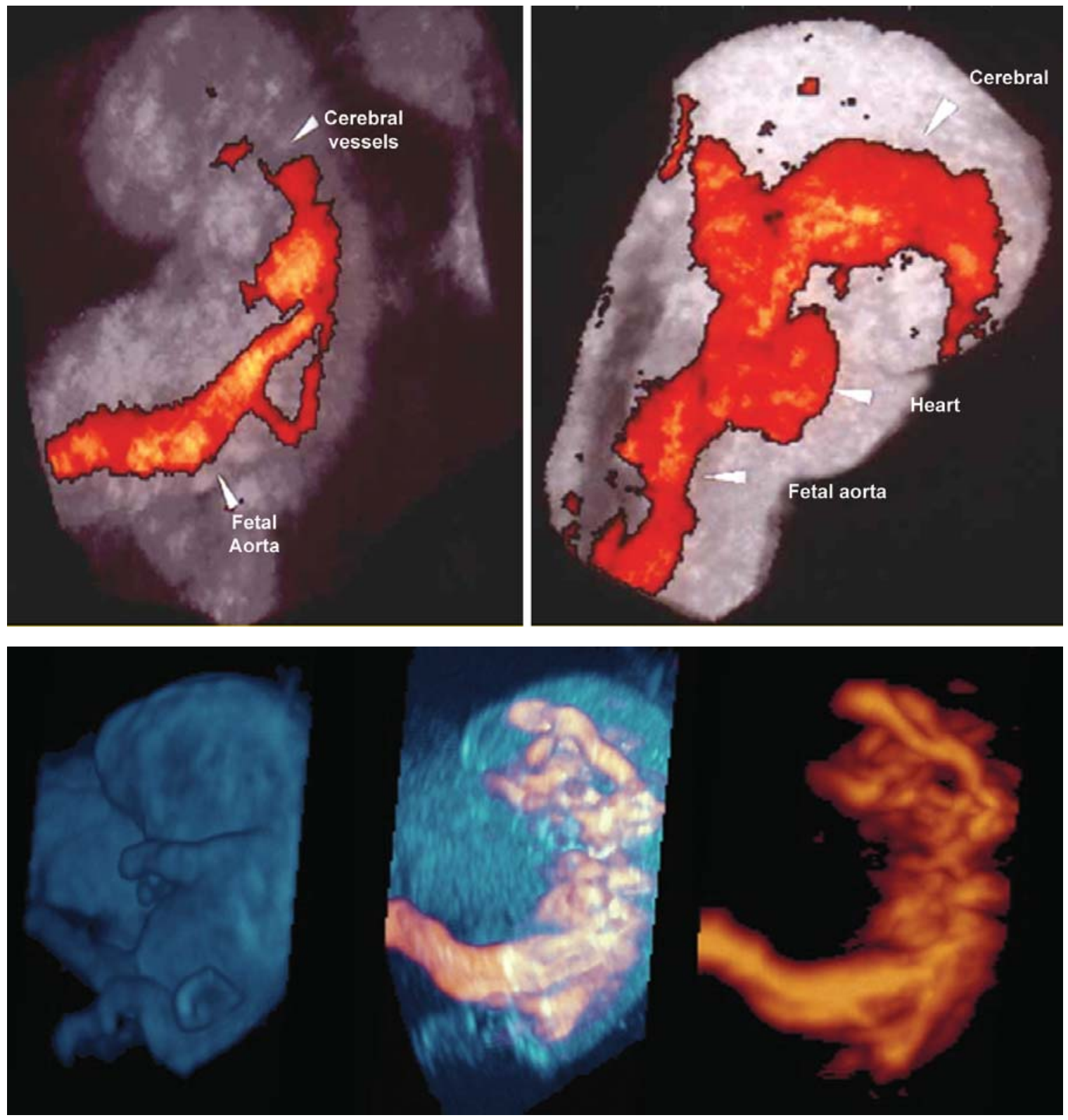

Fig. 18: By using recent 3D power Doppler technology, circulatory orientation can be clearly obtained and the common carotid arteries, internal carotid arteries, cerebral arteries. In the eighth weeks of gestation (left image) cerebral vessels are for the first time depicted. Furthermore, vascular anatomy can be seen in increasing details. Note the abdominal aorta with umbilical artery branching at the caudal pole. Umbilical vein can be followed from the abdominal umbilical insertion through the fetal liver and ending bellow the heart

\section{REFERENCES}

1. Pooh RK, Pooh K, Nakagawa Y, Nishida S, Ohno Y. Clinical application of three-dimensional ultrasound in fetal brain assessment. Croat Med J 2000;41:245-51.

2. Kurjak A. The beginning of human life and its modern scientific approach. Clin Perinatol 2003;30:27-44.

3. Johnson MJ. Implantation and the establishment of the placenta. U: MJ Johnson, BJ Everitt, Essential reproduction. Oxford: Blackwell science 1999:173-93.
4. Shiota K. Early human development: An overview. U: A Kurjak, FAChervenak. Controversise on the beginning of the human life. New Delhi: Jaypee brothers medical publishers 2008;151-66.

5. Moore KL. The first two weeks of human development. U:KL Moore, TVN Persaud, K Shiota. Color atlas of clinical emrbyology. Philadelphia: WB Saunders company 2000;1-12.

6. Suchanek E, Simunic V. Gamete, oplodnja i rani razvoj zametka. U: V Simunic. Ginekologija. Zagreb: Naknada Ljevak 2001:6177. 

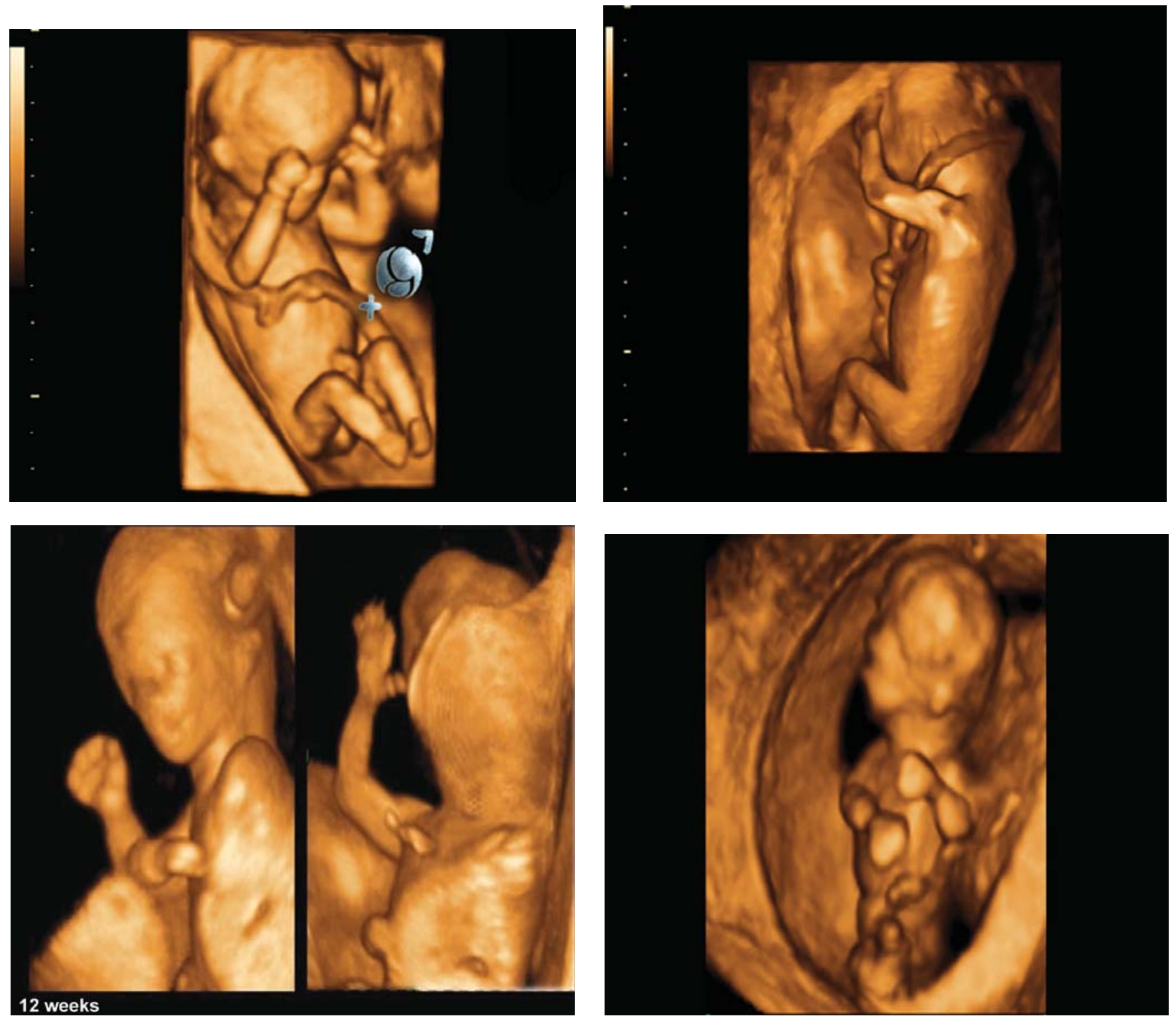

Fig. 19: From 10 to 12 weeks of pregnancy complex body movements appear. Movements of limby toward the head, flexion and extension and elbows and knees can be depicted

7. Sadler TV. Od ovulacije do implantacije. U: TW Sadler. Langmanova medicinska embriologija. Zagreb: Školska knjiga 1996;23-41.

8. Prasada SV, Skinnera M, Carinoa C, et al. Structure and function of the proteins of the mammalian zona pellucida. Cells Tissues Organs 2000;166:148-64.

9. Zohav E, Bar-Hava I, Meltcer S, et al. Early endometrial changes following successful implantation: 2 and 3-dimensional ultrasound study. Clin Exp Obstet Gynecol 2008;35:255-56.

10. EH Ng, Chan CC, Tang OS, et al. The role of endometrial blood flow measured by three-dimensional power Doppler ultrasound in the prediction of pregnancy during in vitro fertilization treatment. Eur J Obstet Gynecol Reprod Biol 2007;135:8-16.
11. Ng EH, Yeung WS, Ho PC. Endometrial and subendometrial vascularity are significantly lower in patients with endometrial volume $2.5 \mathrm{ml}$ or less. Reprod Biomed Online 2009;18:262-68.

12. Kurjak A, Pooh RK, Merce LT, Carrera JM, Salihagic-Kadic A, Andonotopo W. Structural and functional early human development assessted by three-dimensional and fourdimensional sonography. Fertil Steril 2005;84:1285-99.

13. Blaas H-G, Eik-Nes SH, Isaksen CV. The detection of spina bi?da before 10 gestational weeks using two- and three-dimensional ultrasound. Ultrasound Obstet Gynecol 2000;16:20-29.

14. Pretorius DH, Nelson TR, Baergen RN, Pai E, Cantrell C. Imaging of placental vasculature using three-dimensional ultrasound and color power Doppler: A preliminary study. Ultrasound Obstet Gynecol 1998;12:45-49. 
15. Kurjak A, Kupesic S, Hafner T. Intervillous blood? Ow in normal and abnormal early pregnancy. Croat Med J 1998;39:10-14.

16. de Vries JI, Visser GH, Prechtl HF. The emergence of fetal behaviour: I. Qualitative aspects. Early Hum Dev 1985;12:99120.

17. Kurjak A, Azumendi G, Andonotopo W, Salihagic-Kadic A. Three- and four-dimensional ultrasonography for the structural and functional evaluation of the fetal face. Am J Obstet Gynecol 2007;196:16-28.
18. Kurjak A, Vecek N, Hafner T, et al. Prenatal diagnosis: What does four-dimensional ultrasound add? J Perinat Med 2002;30:5762 .

19. Kurjak A, Miskovic B, Stanojevic M, Amiel Tison C, Ahmed B, Azumendi G, Vasilj O, Andonotopo W, Turudic T, SalihagicKadic A. New scoring system for fetal neurobehavior assessed by three- and four-dimensional sonography. J Perinat Med 2008;36:73-81. 